\title{
La EdUCACIÓN SEXUAL de LOS PÚBERES: UN IMPERATIVO PARA SALVAR EL CUERPO DE LA NACIÓN EN LA ARGENTINA DE LAS PRIMERAS DÉCADAS DEL SIGLO XX
}

\section{The sex education of the pubbers: an imperative to save the body of the nation in Argentina in the first decades of the 20th century}

http://doi.org/10.33255/25914669/582

Lucía Lionetti Instituto de Estudios Histórico-Sociales «Prof. Juan Carlos Grosso» Instituto de Geografía, Historia y Ciencias Sociales - Universidad Nacional del Centro de la Provincia de Buenos

Aires)

Lionettilucia@gmail.com https://orcid.org/0000-0003-4222-4515

Recibido: 21 de septiembre de 2020

Aceptado: 30 de abril de 2021

\section{Resumen}

En el presente artículo se analiza la circulación de discursos orientados a la educación de la sexualidad en la Argentina de las primeras décadas del siglo XX. Bajo la impronta de la influencia de las ideas eugenésicas y el desarrollo de la ciencia moderna, una serie de publicistas promovieron una suerte de policía del sexo avanzando sobre una forma de intervención positiva a través de la educación sexual de progenitores, educadorxs y especialmente la población escolar. Centrados en la preocupación del peligroso pasaje a la sexualidad en la pubertad, buscaron en el recurso educativo una forma de prevención o reencauzamiento de los desvíos 
morales y de patologías sexuales que se ponían en evidencia en esa transición etaria.

Palabras clave: isexualidad - educación - pubertad

\section{Abstract}

This article analyzes the circulation of discourses aimed at the education of sexuality in Argentina in the first decades of the 20th century. Under the imprint of the influence of eugenic ideas and the development of modern science, the publicists promoted a sort of sex police advancing on a form of positive intervention through parent sex education, educators and especially the school population. Focused on the concern of the dangerous passage to sexuality in puberty, they sought in the educational resource a form of prevention or re-orientation of moral deviations and sexual pathologies that were evidenced in that age transition.

Keywords: Sexuality - education - puberty 


\section{Introducción}

En nuestros días asistimos a la emergencia de la educación en la sexualidad como un campo de posibilidades. Después de muchas controversias, en octubre de 2006 el Congreso sancionó la Ley Nacional que crea el Programa Nacional de Educación Sexual Integral (Ley 26.150). ${ }^{1}$ Tal como se reconoce, educar en la sexualidad es una forma de apreciar que la vida sucede en un cuerpo y que podemos entender, analizar y cuidar lo que sucede con nuestros cuerpos, como parte del desarrollo integral de nuestra ciudadanía y nuestras relaciones.

Ahora bien, puede pensarse esta experiencia educativa como una novedad en la Argentina. En el presente trabajo se busca avanzar en ese sentido, a partir de la recuperación de una serie de producciones escritas que circularon en las primeras décadas del siglo $\mathrm{XX}$, donde la sexualidad y su educación devinieron en una temática que ocupó y preocupó a los profesionales pertenecientes a distintos campos disciplinares ${ }^{2}$. Aquellos eran tiempos donde, todo lo concerniente al sexo y la sexualidad era, por excelencia, el reino del inconsciente, de las obligaciones rígidas e incomprensibles, del misterio y también el reino del silencio. Los tabúes ponían en reticencias a la hora de hablar de sexo como de cualquier otro problema humano. Sin embargo, más allá de la incomodidad, médicos, educadores y referentes de las ciencias psi promovieron la educación sexual en las escuelas como un modo de garantizar la salud moral de toda la sociedad.

La sexualidad, asociada al 'dominio de la peligrosidad sexual' (Weeks, 2012), como lo plantea la antropóloga feminista Gayle Rubin (1986), ese gran paroxismo moral del siglo XIX pervive todavía, dejando una profunda huella en las actitudes sobre el sexo. Un tema omnipresente que una y otra vez se lo roza, se lo sugiere y hasta se la deforma sin atreverse -la mayoría de las veces- a abordarla abiertamente a pesar de que nadie ignora, después de Freud, la trascendencia del tema.

Foucault se preguntó de qué modo -en la sociedad occidental desde el siglo XVIIIla sexualidad pasó a ser vista como parte central de nuestro ser, ese privilegiado sitio en donde se encuentra la "verdad de nuestro ser". Lejos de ser el dominio de lo privado, se ha convertido en central para el moderno funcionamiento del poder. La estricta moral que se considera como típica de la burguesía había hecho su aparición en siglos anteriores de la historia y, por lo que concierne al Antiguo Régimen, el repertorio de delitos sexuales perseguido por la Inquisición no se modifica después del siglo XVI. Como explica, no existen, por tanto, razones suficientes para afirmar

I Sobre los desafíos y límites de la implementación de la ESI en las instituciones escolares de Argentina, sobre todo en las escuelas medias ver Morgade, 2019.

2 Un trabajo que analiza la edición para el caso de Argentina, en torno a los años veinte y treinta de textos y folletos mayoritariamente dedicados a la sexualidad, que formaron parte de la Biblioteca Científica de la Editorial Claridad dirigida por Antonio Zamora es el de Múgica, 2017. 
que en el siglo XVII comience una etapa de características marcadamente diferentes de la anterior.

A partir del siglo XVI al XVIII, se asistió a la emergencia de un "discurso sexual" poniendo a la sexualidad en el mapa de la historia política y demostrar. El sexo -palabra con la que enlaza la anatomía, funciones biológicas, conductas, placeres, sensaciones, etc.- devino en la bisagra que articula las relaciones sociales de poder. En la Historia de la Sexualidad se propuso desmantelar la noción de sexo como principio causal y sentido omnipresente que ordena las culturas, y exhibir no su secreto constitutivo sino el funcionamiento ideológico que constituyó el sexo.

En su aproximación del poder en clave relacional que se formula dentro de la red de relaciones que lo sustentan, nos advierte que se asistió a una construcción particular de conocimiento. Al indagar en esa historia del discurso, encuentra que el anatema que arrojó la religión cristiana sobre la actividad sexual en las sociedades del Ancien Regimen desemboca, por el contrario, en una profusión de discursos. Se trata, por tanto, de descubrir y poner esa sexualidad en parte oculta y perdida. El sexo habría quedado silenciado respecto de la acción -parcialmente, como es claro-, pero en cierto modo ese silencio dio origen a lo que podríamos calificar a la proliferación de la literatura pornográfica. Tal como analiza, la hipótesis que pretende hacer coincidir la represión sexual de Occidente con la aparición del modo de producción capitalista nos conducía a una visión de la historia de la sexualidad simplista y con poca base científica (Foucault, 1991).

Otro de los aportes significativos que contribuyeron a desvelar esta cuestión vino de la mano de la teoría feminista al elaborar la categoría de género como una construcción cultural que provee de significaciones y atributos lo masculino y lo femenino. En el interior de la teoría, las cosas al principio parecían estar claras y resultaron productivas para pensar un amplio campo de problemas en cada disciplina. Por un lado, el sexo aludía a una condición biológica inscrita por naturaleza y el género, por su parte, remitía a las operaciones culturales que dan significación a lo femenino y a lo masculino. En esta disposición ideológica el cuerpo sexuado fue y es sin duda la medida básica de este tipo de asignaciones. Sin embargo, después de treinta años de debates y de confrontación de posiciones, la noción de género comenzó a tambalear respecto de aquellas primeras ideas que ubicaban al "sexo" (los rasgos anatómicos diferenciados de hombres y mujeres) como un dato material previo, sobre la cual la cultura desplegaba todo un arsenal simbólico para instalar la diferencia sexual. En los noventa, filósofas como Judith Butler llegan a afirmar que no hay sustancia original y anterior a la cultura, ni siquiera el cuerpo puede evadirse de categorías y lenguajes que le asignen posiciones y lo designan, ya desde el nacimiento. El sexo mismo, para esta teórica, es una construcción que por sí misma dicta y despliega su propia historia.

Las investigaciones científicas más recientes acercan información sobre variantes físicas y fisiológicas que hacen pensar que el sexo biológico es menos fijo de lo que 
se creía y en todo caso está expuesto a una serie de combinaciones más amplia que la dualidad varón-mujer. Las migraciones sexuales no cuentan con la única opción de cambios en el nivel de las apariencias o vestimentas sino también con el auxilio de una ciencia dispuesta a intervenciones concretas sobre la corporalidad. Fuera del secreto, como decía Foucault, las sexualidades "diferentes" hacen del impacto público una política. De allí las preocupaciones de diversas formas de poder (de características específicas pero semejantes en su intervención) por el trazado de fronteras claras entre lo masculino y lo femenino.

En este sentido, cabe recordar que son las instituciones y las personas en su actuar cotidiano quienes ejercen poder, legitimando determinados significados en torno a la sexualidad y heteronormatividad, al precio de la represión o exclusión de otras posibles alternativas. Esto interpela al sistema educativo y a la escuela en tanto institución productora y reproductora de un discurso pedagógico que reconoce ciertos "tipos" de sujetos en detrimento de otros. La propuesta de desnaturalizar la identidad sexual, de no tomar como un dato "natural" el dimorfismo sexual, implica la renuncia a la reivindicación de la normalidad perdiendo el binomio normal/patológico su fuerza.

A la escuela le competía asumir esa misión como un modo de salvarlos de esas posibles desviaciones, producto de su debilidad moral. Con el objetivo de dar cuenta de esas formas de intervención que buscaron implementar estos publicistas y reformadores, a partir del recurso de la educación sexual, en el presente trabajo se analiza, en un primer apartado, algunas de esas propuestas que fueron formuladas por referentes de la pedagogía como Raquel Camaña, Víctor Mercante, Julio Barcos, médicos y divulgadores eugenistas y el psicólogo Aníbal Ponce. A pesar de las distintas derivas profesionales y posturas ideológicas coincidían en la preocupación por los desvíos morales y patologías sexuales. En un segundo apartado, se presentan algunas de esas producciones que abordaron la problemática de la sexualidad de les púberes que transitaban esa peligrosa experiencia que debía ser conocida y orientada para evitar sus posibles desbordes.

\section{La pedagogía como un campo de posibilidades para abordar la sexualidad}

En Argentina, desde el mismo momento en el que la educación pública se conformó como una de las expresiones de mayor alcance del proyecto modernizador de la elite a fines del siglo XIX, aunque conveniente enmascarada, la sexualidad atravesó el currículum de la formación de los futuros ciudadanas y no-ciudadanas. La escuela con su impronta educadora en clave de género, se centró en una cuidada red discursiva y un conjunto de prácticas orientadas a fijar una distribución de roles, funciones, espacios y ámbitos de acción para los niños y las niñas. En ese proceso de construcción del Estado como marco de un ejercicio jerárquico de la vida civil, pública y privada, la masculinidad sin fisuras fue parte indispensable de su organización armónica. Supeditada a su condición de partenaire del varón, las no ciudadanas fueron presentadas bajo la figura de "madres y esposas de ciudadanos". 
De importancia nodal para ese cometido fueron las asignaturas de Higiene, Economía Doméstica, Educación Moral y Cívica y la práctica de Ejercicios Físicos. ${ }^{3}$ Apelando a un conjunto de estrategias el tratamiento de la sexualidad en el ámbito escolar, quedó asociada a la enseñanza de la higiene, ${ }^{4}$ a la prevención de enfermedades venéreas, al dominio del cuerpo, a la formación de hábitos, al fortalecimiento de la voluntad, a la defensa de la familia y los valores morales que reforzaban la idea de castidad, abstinencia y retiro al ámbito doméstico para las niñas y la vida pública para los niños. ${ }^{5}$ Esos comportamientos buscaron imponer una verdad sobre el sexo en tanto "las prácticas reglamentadoras producen a los sujetos que someten sobre la base de un binarismo que intenta suprimir cualquier trastorno de las hegemonías: heterosexualidad, reproductiva y médico-jurídica" (Butler, 1999, p. 101).

Sobre estas cuestiones trabajó la pedagoga socialista Raquel Camaña ${ }^{6}$ cuando proclamó que la escuela debía asumir su función social de preparar a mujeres y hombres para que "sepan amar" y cultivar el "jardín del matrimonio" (Camaña, 1916, p.10). ${ }^{7}$ Dirigió su preocupación a la figura de la madre para que conociera los riesgos a los que se exponían las alcohólicas, las sifilíticas o las tuberculosas que cometían "el crimen de procrear". Se debían conocer las medidas que previnieran que se envenenara la sangre materna bajo la influencia del trabajo exagerado y violento que contribuía a la degeneración de la raza humana. Influenciada por el eugenismo positivo que promovió la prevención, ${ }^{8}$ entendía que, si la maternidad, no se la asumía con responsabilidad devenía en un acto negativo, de funestas consecuencias para ella, su prole y la sociedad en su conjunto.

La vulgarización de la higiene integral, incluyendo la puericultura, la educación y la instrucción sexual, permitiría ver a los niños y niñas que el problema de los

\footnotetext{
3 Al respecto ver Lionetti, 2007.

4 Los vínculos entre la medicina y la educación dieron como resultado final que los médicos se convirtieran en pedagogos y los educadores en higienistas. Al respecto, ver Di Liscia y Salto, 2004.

5 Un trabajo en el que se explora la producción y circulación de manuales sobre la sexualidad es el de Múgica, 2017.

6 Raquel Camaña (Buenos Aires: 1883- 1915). Se graduó como maestra y profesora en la Escuela Normal Nacional de La Plata. Luego, se diplomó en la Escuela Normal de Lenguas Vivas. En 1910, concurrió al Congreso de Higiene Escolar celebrado en París, llevando la representación oficial del gobierno argentino. Colaboró en revistas del país y del extranjero. Parte de su trabajo ha sido compilado en los "estudios de pedagogía social", las "impresiones de viaje" y la "crítica literaria". Como referente de la primera ola feminista, fue defensora de la educación integral de la mujer y cuestionó a la escuela que propagaba la guerra a expensas de los valores humanos. Su figura fue analizada por Southwell, 2015, pp. 109-124.
}

7 Sobre debates médicos en torno a la educación sexual de la mujer y la práctica anticonceptiva ver Nari, 1996. Sobre el tratamiento del cuerpo femenino por parte del discurso médico se puede consultar: Nouzeilles, 2003 y Barrancos, 1991 y 2001.

8 El tema de la eugenesia cuenta con numerosos aportes solo a modo de referencia puede mencionarse el de Stepan, 2005. Una revisión que analiza las diferentes recepciones del eugenismo en Miranda y Vallejos, 2012. 
sexos se lo debía considerar bajo su doble aspecto "masculino" y "femenino". Dos seres diferentes, inversos, complementarios, equivalentes que demostrarían que hay progreso sexual cuando más se ahondaran los caracteres específicos comprendiendo que lo determinante en la mujer pasaría por la maternidad. Por allí pasaba la marcha extraviada del feminismo, "verdadero masculinismo", que convertía a la mujer en la caricatura del hombre (Camaña, 1916, p. 27).

Sobre la base del aporte de las Ciencias Naturales, se debía enseñar la ley de la vida, de la fecundación, del desarrollo, del amor en la reproducción de las plantas, en las clasificaciones científicas que casi todas se basan en los órganos de reproducción; en la metamorfosis de los insectos, en las costumbres de las abejas, de las hormigas. En esa "verdad natural" estaba reservado el reino de la libertad de acción. La naturaleza, científicamente interpretada, conduciría al adolescente a amar la ley de la vida, de la fecundación, del desarrollo y a medir la responsabilidad de la transmisión consciente de la energía que diviniza al hombre. La mujer y el varón compartían el deber de ser padres responsables. El trípode sobre el que edificó su doctrina fue: conocimiento-conciencia-voluntad, en tanto lo atinente al acto sexual trascendía lo estrictamente individual para transformarse en un problema de orden social. La enseñanza debía ir más allá de la prevención y la higiene, encarada como una formación de la conciencia, de los deberes y la responsabilidad colectiva. Partícipe del clima de ideas eugenésicas, buscó combatir el "delito natural" contra la especie, provocados por los llamados "venenos raciales": la sífilis, la tuberculosis y el alcoholismo. La escuela debía promover la protección de la procreación, la maternidad y la infancia (Camaña, 1916, p. 69).

Para quienes participaron de las medidas preventivas (higiénicas) y profilácticas (eugenesia), el silencio no era conveniente porque ponía en riesgo la virtud femenina y la salud de todo el cuerpo social. De allí que el tema y los debates aparecía recurrentemente en la revista educativa del Consejo Nacional de Educación, El Monitor de Educación Común. Uno de los escritos más sugerentes es el que se publica a pedido de la Liga de Profilaxis Argentina (en adelante LAPS), y que fuera difundido primero en Uruguay. ${ }^{9}$ El presidente de la Liga pidió especialmente al Consejo Nacional de Educación argentino autorización para su publicación con el propósito de que lo leyeran las maestras y lo divulgaran entre sus alumnas. El artículo de la francesa Jeanne Leroy-Allais ${ }^{10}$-publicado originalmente en los Estados Unidos- fue traducido por el puericulturista Emilio Coni bajo el título "De cómo he instruido a mis hijas: la educación de las niñas americanas" en los Anales de Instrucción Primaria

9 Sobre la cuestión de las iniciativas de abordar la educación sexual en las instituciones escolares del Uruguay ver Darré, 2005. 
por iniciativa de la Dirección de Enseñanza Primaria y Normal de Uruguay. La LAPS apeló a la publicación oficial para que sea conocido por el personal docente y para que fuera impreso en forma de opúsculo y difundido entre las madres. El texto vuelve a reforzar la alianza que la madre debía tener con el médico para que se informara debidamente en la educación de su hija (Donzelot, 1994). Así, se señala:

"[...] Esta enseñanza se dice puede ofrecer peligros. [...] ¿Acaso las estudiantes de medicina y las enfermeras son, por haber sido instruidas, más pervertidas que esas doncellas delante de las cuales uno no se atreve a decir nada? [...] Lo que es pernicioso para la juventud es conocer el libertinaje antes de estar en edad de apreciar el amor; es por considerar el amor no como obra de procreación, pero sí como obra de voluptuosidad" (El Monitor de la Educación Común -En adelante, MEC-, Año 40, Tomo 82-83, 1922, pp. 195).

En el relato, se presenta a Genoveva de trece años quien recibe la información de su madre, para que no llegara "al matrimonio desconociendo sus obligaciones futuras" (MEC, Año 40, Tomo 81 y 82, 1922, p. 193). El conocimiento combatía la ignorancia. La madre, atenta a los cambios que mostraba su hija como la fatiga sin causa, la distracción, la palidez y sus frecuentes pesadillas nocturnas, se asesora por su cuñado médico quien le diagnosticó que era a "causa de la edad". La madre explica a la hija cómo eran los órganos reproductores femeninos y sus funciones, buscando tranquilizarla en ese "pequeño fastidio momentáneo que sufría" y dándole la seguridad de que todo funciona bien" (MEC, Año 40, Tomo 81 y 82, 1922, p. 193). No se soslayan temas como el embarazo, el parto, los cuidados para su salud y el cuerpo femenino, las vestimentas adecuadas, el decoro necesario que debía mostrar una joven que cuidara su respetabilidad.

Pero también al hombre le cabían responsabilidades en sus actos como padres 0 futuros esposos, puesto que

"[...] hay que criticar a aquellos que por descuido siembran la enfermedad a su alrededor [...] El mal que nos ocupa es, sobre todo, mal de libertinaje [...] las primeras víctimas las jóvenes. [...] Así los padres que entregan a sus hijas únicamente por ventajas materiales, por la gloria, por el dinero, son imbéciles 0 criminales; imbéciles de no conocer y prever las funestas consecuencias de ciertas enfermedades; criminales, si previéndolas no las toman en cuenta. Es cuestión de imponer a los hombres que se casan un certificado médico comprobando su buen estado de salud" (MEC, Año 40, Tomo 81 y 82, 1922, p. 198).

El varón y la mujer debían prepararse para protegerse y cuidarse en su vida amorosa, sabiendo que su descuido afectaba a toda la sociedad. Lo sugerente del artículo es que, esa figura de la "maternidad eugénica", refuerza la autoridad femenina como 
educadora y, con ello, su poder interno dentro de la familia.

El temor a la transmisión de las enfermedades venéreas y a la degeneración de la raza precipitó ese interés por llevar la temática de la sexualidad al ámbito escolar. ${ }^{11}$ Fue el objetivo de la Liga Argentina de Profilaxis Social al promover el dictado de conferencias (dirigidas en gran medida a los profesores y al magisterio), la publicación de folletos y la proyección de películas. En las conferencias (auspiciadas por el Ministerio de Instrucción Pública y el CNE) se hablaba de fomentar la abstinencia sexual en los jóvenes educándolos en el control de las tentaciones, las pasiones y bajos instintos. Educando en el poder de la voluntad, se garantizaban pilares como: "el vigor, el amor, el casamiento, el hogar, la familia, la vida, el amor filial y fraternal" (LAPS, "El poder del hombre", Folleto, no 11, Buenos Aires, 1921, p. 22). Había que evitar el "crimen" de la "degradación de la especie", un delito contra la humanidad y la raza, por lo cual advertía a los jóvenes:

"[...] pronto seréis padres. A vuestra segunda infancia, va a suceder la llamada pubertad. [...] Vais a ser dominados por el Genio de la Especie. [...] ese genio va a determinar en vosotros, impulsos más o menos imperiosos, [...] ciertamente ciegos.

Pues bien nosotros puericultores deseamos ilustraros [...] Pues sabedlo, para ser hombre verdadero, completo ciudadano, es menester ser padre de familia.

[...] A la obscuridad (sic) debe suceder la luz; a la barbarie debe suceder la verdadera civilización. A la hipocresía queremos sustituir la verdad. [...] así tendremos absoluta convicción de ser los [...] instructores de la más alta moral individual y social" (LAPS, "A la juventud. Para el porvenir de la raza". Folleto $\mathrm{n}^{0}$ 4, Buenos Aires, 1921, p. 12). ${ }^{12}$

Aún más desafiante y contundente fue la propuesta del educador y pedagogo anarquista Julio Barcos ${ }^{13}$. En la revista Cuasimodo, publicó una serie de artículos

\footnotetext{
11 Un interesante análisis de esas preocupaciones sociales que generaron las enfermedades de transmisión sexual en la ciudad de Buenos Aires, entre 1920 y 1940 es el de Queirolo, 2013, pp. 67-87.
}

12 Esta conferencia que se publicó en el folleto de la Liga fue dictada por el Dr. Adolph Pinard, miembro de la Academia de Medicina de París (Versión en español del Dr. Emilio Coni). Sobre la figura de Emilio Coni ver Armus, 2007.

13 Julio Barcos (Buenos Aires, 1883-1960). Se graduó como maestro y pedagogo en la Escuela Normal de Paraná. Militó en las filas anarquistas, participando de la creación de la Escuela Libertaria. Organizó la Liga Nacional de Maestros y fue uno de los principales impulsores de la Confederación del Magisterio. Se ausentó del país por un breve período, en Panamá fue director de la publicación de la revista Cuasimodo-. A su regreso se aleja de las filas libertarias, producto de sus desinteligencias internas, y se acercó al radicalismo yrigoyenista actuando incluso como parte de la burocracia educativa. Autor de numerosas obras entre las que podemos destacar: Cómo educa el Estado a sus hijos. La felicidad del pueblo es la suprema ley (cuadros de psicología política y social), Otero y Cía., Buenos Aires, 1915. Régimen Federal de la Enseñanza. Hacia una nueva legislación escolar", Editorial Cátedra Lisandro de La torre, Buenos Aires, 
referido a la cuestión de la sexualidad específicamente en la mujer. ${ }^{14}$ En ellos comentaba que, la ignorancia que prevalecía en la sociedad con respecto a las cuestiones sexuales era la consecuencia del "crimen del silencio" impuesto por la burguesía conservadora y los curas a toda la sociedad. Esa ignorancia, conducían a consecuencias indeseables como las "desviaciones", entre ellas, la homosexualidad masculina. ${ }^{15}$ De allí la urgencia de una educación sexual que "[...] equilibra su salud y contribuye al desarrollo armonioso de su personalidad sentimental [...]" (Barcos, 1925, p. 197).

Abordó aspectos como el de la castidad, la virginidad, el matrimonio, la moral burguesa, la promiscuidad, la prostitución, los delitos contra la mujer, la maternidad, la familia, la educación sexual en las escuelas, el papel de la religión y de la Iglesia Católica, el machismo, la seducción, el incesto, el adulterio, las sociedades matriarcales, la literatura erótica y sentimental, etc. Como sostiene Barrancos, "El discurso sobre la sexualidad producido por el anarquismo hacia finales del siglo pasado y principios del XX estaba ligado a su manifiesto anti clericalismo, el propósito de una secularización y en la devoción al positivismo-evolucionismo, fijados en la admiración a Darwin y, aunque menos, a Spencer también" (Barrancos, 1990, p. 241). En el caso de Barcos, apeló a los aportes de la psicología, la biología, el higienismo, la etnología, la antropología, la psiquiatría (con una breve referencia a Freud), la filosofía y la historia a los efectos de argumentar que, la castidad como la virginidad genera enfermedades en las mujeres como la histeria, el nerviosismo, la debilidad, debido a la imposibilidad de ejercer libremente su sexualidad sin restricciones de ningún tipo. En los hombres, el impedimento de satisfacer sus deseos sexuales los empuja al prostíbulo en donde caen víctimas de las enfermedades venéreas, la tuberculosis, la sífilis, y a la homosexualidad, considerada una degeneración psicológica.

La virginidad y la idolatría serían las responsables de esa escasa evolución biológica de la sociedad. Si todo el andamiaje de la sociedad capitalista se apoya en la propiedad privada, según Barcos, las relaciones entre los géneros convierten a la mujer en propiedad del hombre a través del contrato matrimonial. Ese sometimiento acabaría con la revolución social que derrumbara al capitalismo, la explotación burguesa y sus valores morales. La nueva libertad sexual promovería una sociedad

1957. Escribió artículos en revistas anarquistas como Escuela Popular y en diarios. Sobre las propuestas educativas del anarquismo puede consultarse los conocidos trabajos de Barrancos, 1990; Suriano, 2004; Sardú, 2008; Pita González, 2012). Coni ver Armus, 2007.

14 Ver "Una encuesta que levanta roncha. Polémica entre mujeres.", "Dos madres - dos morales - dos culturas", Cuasimodo, No 18, mayo de 1921; "Cuando se emancipen las mujeres", Cuasimodo, № 23, septiembre de 1921, ediciones digitales BAEL (Biblioteca Archivo de Estudios Libertarios), Federación Libertaria Argentina.

15 Sobre el límite claro de la homosexualidad respecto a la radicalidad del anarquismo ver Fernández Cordero, 2017. 
sin perversiones16, donde no se daría el asesinato pasional, la violencia, el adulterio, la violación, todo fruto de la monogamia y las prohibiciones morales que pesan sobre las personas y su sexualidad. El pudor femenino, reflejo de los valores morales impuestos por medio de la educación, distrae la atención sexual del hombre sobre la mujer exacerbando el deseo sexual (Barcos, 1925, p. 50). El afán de las mujeres por las cuestiones del vestido, la moda, los perfumes, los tocados, el peinado, no proviene del deseo de ocultar las partes consideradas inmorales, sino del deseo de "exhibir", sugerir la belleza física para aumentar su poder de seducción sobre los hombres. Ese pudor femenino, al ser fruto de la moral y la costumbre que se vuelve cotidiana, desaparecerá cuando se provoque esa revolución cultural.

Las vírgenes y las prostitutas serían las dos caras de la misma moneda. La existencia de unas, las vírgenes, es la causa de la otra, las prostitutas. La castidad de unas, determinadas a conservar su virginidad como prenda para conseguir hombre para el matrimonio, es lo que provoca la aparición de las otras, en las cuales los hombres van a saciar su deseo y surge un perverso mercado sexual (Barcos, 1925, p. 124). Claramente, las principales víctimas de esa situación eran las mujeres pobres.17

Pero también el hombre se vería obligado a llevar una vida humillante: 0 se convierte en un "Don Juan Tenorio", el eterno seductor de mujeres de otros quien no respeta virtud, honor ni propiedad privada, el ladrón de la propiedad ajena, el "anarquista del amor" hasta que cae en el matrimonio para convertirse en un arduo vigilante de su mujer y correr a los donjuanes que vengan a robar su propiedad. 0 es el "Otelo", el asesino de mujeres, quien para defender su honor humillado, golpea o mata a su mujer sin que sea castigado por la justicia. El hombre proletario esclavo de su patrón, ha convertido a su mujer en su esclava doméstica.

En sintonía con las posturas de algunas feministas de la época, planteó la necesidad de fomentar la coeducación sexual. Sin embargo, cuando habló de desviación, anomalías, homosexualidad lo hizo de ese sustrato cultural común y un prisma científico que divulgó la "naturalidad" de la norma heterosexual. Su reivindicación de la libertad sexual se orientaba a erradicar toda forma de perversión. Para "corregir" los impulsos perversos era clave formar la sexualidad en la pubertad. Aquella era la edad donde jovencitos y jovencitas entraban en la zona del peligro y se volvían peligrosos.

\section{La peligrosa sexualidad de los púberes}

\footnotetext{
16 Un aporte que también advierte este temprano discurso sobre la libertad sexual, a partir del análisis de los discursos de los médicos Juan Lazarte y Manuel Martín Fernández en años treinta y cuarenta, como una clara anticipación al movimiento de la llamada Revolución sexual de los años 1960 es el de Ledesma Prietto, 2017.

17 Tal como afirmaba: "Mientras subsista este maravilloso régimen económico, que solo abre tres puertas a las mujeres pobres: la subasta del matrimonio, la esclavitud del taller o la mancebía, no hay que pensar en la posibilidad de abolir la prostitución. Este cáncer desaparecerá solo con la muerte del capitalismo". Barcos, 1925, pp. 151-152.
} 
Claramente el centro de preocupación era ese pasaje a la adolescencia signado por los cambios fisiológicos, emocionales y psicológicos, del que daban cuentan los y las púberes en el espacio escolar. En términos del pedagogo Víctor Mercante ${ }^{18}$ había que develar "los secretos del caos y las normas del orden y la armonía, indispensables para que la escuela fuera eficaz" (Mercante, 1917, p. 15). Por eso promovió una investigación escolar-antropológica convirtiendo al aula en un laboratorio humano para concluir que, el desánimo del niño, su espíritu de desorden y pereza se podrían revertir con métodos basados en estímulos rápidos, económicos, eficaces y no penosos, sustentados en la razón nacida de la experiencia. Aquellas experiencias fueron anticipaciones de prácticas como las de la médica Telma Reca quien, entre los años treinta y cuarenta, apeló al ámbito educativo para observar e individualizar las conductas "antisociales" que conducían a la delincuencia como la de aquellos considerados anormales (Ramaciotti, 2018). ${ }^{19}$

Advertía que los niños entre 11 a 12 años tenían predisposición a la indisciplina por sus sobrantes de motricidad que coincidían con el período sexual y belicoso que atravesaban. Sobre la base de sus estudios sobre el púber elaboró su teoría pedagógica de la que se nutrió la reforma del ministro Carlos Saavedra Lamas impulsada en 1916. Siguió los censos educativos que mostraban cómo, particularmente los varones, concluían su escolarización primaria en el $4^{\circ}$ grado con lo cual promovía la escuela intermedia para salvar ese inconveniente. Su planteo se inspiraba en lo que Dewey había sentenciado como el "despilfarro de la educación". A diferencia de otros normalistas argentinos, que apostaron a la capacidad transformadora de la educación, estimó que la escuela no podía modificar el instinto.

La psicología, la medicina y la fisiología le permitieron explicar que, entre los 12 y 16 años, se alcanza "la maturación sexual", aunque las deformaciones de las costumbres civilizadas la extendían hasta los 25 años. La Fisiología le permitió comprender que en esa etapa se operaba una evolución rápida de los órganos genitales, y una modificación profunda de la constitución orgánica, de allí ese brusco cambio que impulsa a los adolescentes al juego por placer y por necesidad, para gastar energía física. La escuela tradicional no se adaptaba a esas necesidades enclaustrando a los púberes pero la intermedia, con distintas actividades en el taller o la granja, podía canalizar ese sobrante de energía.

En el orden mental los púberes pasaban por una depresión, producto del "cretinismo transitorio", donde -en el caso de las niñas- la imaginación se extravía en "raras

18 Víctor Mercante (Merlo, 1870 - Los Andes, 1934). Graduado como maestro y profesor en la Escuela Normal de Paraná. organizó la Sección Pedagógica en la Universidad de La Plata, basamento de la actual Facultad de Humanidades y Ciencias de la Educación. Decano de la Facultad de Ciencias de la Educación. presidió la Sociedad Psicológica de Buenos Aires. En 1918, presidió la Sociedad Psicológica de Buenos Aires. Fue autor de numerosas obras pedagógicas. Su figura fue analizada en Lionetti, 2006. 
sentimentalidades", haciéndose más reservadas, temerosas, vergonzosas o bien, autoritarias y coquetas. Era la edad de las amistades tiernas, del amor romancesco, de las ambiciones y de las grandezas. Por el contrario, la anatomía y fisiología del varón sufren cambios definitivos que lo afectan a nivel psicológico. Concluía que, a partir de la pubertad, el varón llega al apogeo de los atributos intelectuales y morales de su masculinidad, en el caso de la mujer adopta los rasgos peculiares de su sexo.

En absoluta sintonía con la cultura patriarcal de aquellos tiempos modernos, sostenía que la despreocupación moral en que vive el alma infantil de la joven le sucede el conocimiento de su situación sexual. El secreto instinto de su verdadera misión, acentuaría la vida interior con excesos de meditación, melancolía y la angustia expresada en llantos inmotivados. Su ternura se consagra en determinados pensamientos y personas. Ese exceso sentimental se traduce, en algunos casos, en misticismo.

El varón, se muestra presuntuoso, turbulento, osado, soñador, "ardiente de inasibles quimeras". En el joven se hipertrofia su yo de allí que se siente hombre y alimenta sus ambiciones. Por esa razón el púber se indisciplina, siendo incapaz de persistir en una ocupación o actividad cualesquiera. Ese "desorden mental" lo conduciría a una progresiva inferioridad intelectual, de allí la conveniencia de ejercitar las aptitudes manuales.

Según sus observaciones, la atención, la voluntad y la constitución de los centros perceptivos distarían en función de los sexos. La atención de la mujer es más concentrada en el período infantil, y se vuelve más indirecta y dispersa en la pubertad, ocurriendo lo contrario en el hombre. Un diagnóstico oportuno para una reforma que apuntó a la continuidad de los estudios de los varones en la Escuela Intermedia y, eventualmente, para que unos pocos siguieran el Colegio Nacional.

A su vez, tanto en el varón como en la mujer adolescente, observó que existe una preferencia por ejercitar las manos antes que estudiar materias. Las jóvenes le habían mostrado una inclinación a la pintura, y la aversión a los "quehaceres femeniles" (modista, bordadora). Se sentirían atraídas por la Naturaleza, aborreciendo la fatiga por los que buscan ocupaciones amenas y un tanto románticas. Tareas como la telegrafía y la costura les resultarían monótonas. Sus preferencias por leer Historia y Literatura, le indicaban que serían menos propensas a las actividades manuales que los varones. De allí que la escuela debía adaptarse a esas dos grandes coordenadas (Mercante, 1917, p. 239).

No dejó de asociar esa profunda crisis de la pubertad como una situación que promovía las inclinaciones "perversas":

"[...] es la edad en la que, el amor ofrece esas extrañas perversiones conocidas bajo el nombre (sic) de homsexualidades y que atacan en forma de amistades solitarias, primero de emoción fiamesca después, para resolverse, por último, en uranismo (...). La función de las glándulas genésicas [...] trae consigo al 
libidinoso [...] El onanismo [...] es un vicio casi habitual del adolescente [...] que reclama métodos previsores, como la vida en campaña y una educación sexual" (Mercante, 1917, pp. 184).

Una edad en la que confluirían virtudes sublimes y acciones heroicas pero también, perversidades y extravíos condenables. Los sentimientos estéticos, vinculados íntimamente con la vida sexual, sufren un profundo cambio al comienzo de la pubertad, de allí que sería imprescindible idear un plan de contenidos y estrategias didácticas, basados en la selección sexual, en la selección intelectual, en el mejoramiento de la especie, en el mejoramiento de los conceptos.

En las Escuelas Intermedias se formaría al nuevo luchador sin recelo para el trabajo. Con el dictado de dos o tres horas al día de contemplación atenta, de dos o tres horas de ejercitación eficaz, de lectura de composición, de dibujo, de educación estética, de educación científica (ciencias naturales, geografía, física), realizadas "bajo el cielo como techo", se vigorizaban el razonamiento y la voluntad. Debido a esa "naturalización" del sexo no se debía promover una educación más práctica orientada fundamentalmente a los varones. Otro era el rumbo para las mujeres que recibirían una educación básica hasta el $4^{\circ}$ grado.

Otro referente de su tiempo que se ocupó de estas cuestiones fue Aníbal Ponce ${ }^{20}$ que estudió la psicología de la adolescencia. Crítico de la escuela pública -y con evidentes distancias ideológicas- tuvo algunos puntos de encuentros con Mercante a la hora de analizar la sexualidad de púberes y adolescentes. Preocupado por capacitar al magisterio en sus conocimientos sobre sus alumnos dictó una serie de cursos en el Colegio Libre de Estudios Superiores. La psicología genética de Ponce no fue evolucionista, en el sentido de Ingenieros, donde el eje central de análisis es la filogénesis, sino evolutiva a la manera de Piaget donde prima el análisis ontogenético. Las diferencias en las funciones psicológicas a lo largo del desarrollo del individuo se ubicaron en estos textos como un problema conceptual central a resolver, resistente al reduccionismo biológico. La última etapa de la psicología ponciana estuvo fuertemente centrada en la temática de la adolescencia y la juventud. Entendía a la adolescencia como ese momento vital, transformador de la personalidad, aunque su énfasis pasa por la vinculación del individuo con la sociedad.

La puericia era ese pasaje donde se liberan los niños de pensamientos

20 Aníbal Ponce (Buenos Aires, 1898-1938). Ensayista, psicólogo, profesor y político argentino. Dirigió junto a José Ingenieros la Revista de Filosofía. Sus ensayos cultivaron el género de la biografía, como: "La vejez de Sarmiento", "Sarmiento constructor de la nueva Argentina", "Para una biografía de Ingenieros". Textos psicológicos como: "La gramática de los sentimientos", "Problemas de psicología infantil", "Ambición y angustia de los adolescentes", "Diario íntimo de una adolescente" y de interpretación socio-cultural como: "Humanismo burgués y humanismo proletario", "Educación y lucha de clases", así como una serie de conferencias y ensayos recogidos en el volumen "El viento en el mundo". Sobre el lugar de Ponce en la recepción y desarrollo de un campo de las ciencias psi en Argentina existen varios aportes, de los que podemos mencionar Vezzetti, 2007; Dagfal, 2009. 
irreflexivos y egocéntricos. El mundo de la fabulación de la niñez, en el cual se vivía realizando sus deseos, quedaría atrás. Más coherente en su mentalidad, el niño de once años se mantiene seguro de sí mismo porque no le exige a la vida más que lo actual y lo próximo. Pero, sin embargo, tal como argumenta esa serenidad y confianza darán paso a la desolación, la inquietud y el desconcierto. Si bien apela a la perspectiva genética a la hora de abordar la psicología del adolescente, su análisis se centra en el conflicto de tendencias emocionales, moduladas por las relaciones sociales, que forman parte de esa experiencia del adolescente. Se reserva la palabra pubertad para designar el comienzo de la función reproductora, la pubertad sería un momento de la adolescencia, pero de ningún modo su iniciación ni mucho menos su causa (Ponce, 1934, pp. 182-186).

El comienzo de la tendencia sexual en los adolescentes era un signo de madurez orgánica, dejando para mucho más tarde el problema del amor como expresión de la personalidad desarrollada. Esa es su crítica a Freud, ${ }_{1}^{21}$ no niega que exista ya en los niños una curiosidad sexual, pero pronto se distancia. La curiosidad de los niños no respondería como en los adolescentes a un imperativo de su propio cuerpo, sino en especial a la torpeza o hipocresía del adulto que de alguna manera le ha hecho sentir algo prohibido, secreto, impenetrable. Lo que seduce no es el problema del sexo en sí; le atrae lo desconocido. En un ingenioso comentario, sostiene que, la atracción de lo prohibido es tan intensa en los niños, que resulta significativa la respuesta de una niña de cuatro años, Mignon, a quien la abuela le enseñaba a rezar el 'Padre Nuestro'. Al hacerse repetir varias veces 'y no nos deje caer en la tentación', la niña dijo: 'yo quiero ver esa tentación aunque me caiga'.

El descubrimiento de una nueva conciencia de su cuerpo pone al adolescente sobre el camino de la vida interior que, lejos de identificarse con el desinterés del esquizofrénico, muestra una profunda curiosidad hacia los nuevos estados mentales que le inquietan y que le obligan momentáneamente a alejarse de las cosas para preparar a su regreso un contacto más logrado.

Reconoce en los juegos infantiles, como en los juegos animales, el carácter de una preadaptación de las funciones que el adulto tendrá más tarde que cumplir en serio. El peso de esa cultura patriarcal hace mella en su pensamiento cuando comenta que, la niña que juega a las muñecas se anticipa a la madre en cierto modo. A medida que la memoria y la experiencia aumentan, las tendencias exigen para tales juegos satisfacciones cada vez más imaginarias. De allí que, su preocupación más viva, su ambición y su angustia, consistirá precisamente en trasladar los sueños a la realidad.

El adolescente asiste a un estado de angustia, producto de la incertidumbre sobre

21 Recordemos que el descubrimiento freudiano derribó la pretendida inocencia infantil y, en su lugar, apareció esta imagen del perverso polimorfo. Para Freud, al niño le falta un saber sobre el sexo que el adulto no le da y ahí situó el problema en este primer momento. Lo traumático de la sexualidad estaba en una falta de saber. En su artículo publicado en 1907, "El esclarecimiento sexual del niño", postuló que, una adecuada información al niño sobre la sexualidad podría evitarle sufrimiento y neurosis. 
su destino de modo tal que, si el adolescente la conoce muchas veces, no es porque el equilibrio de su organismo sufre cambios incesantes, sino porque se adelanta al futuro dudando de sí mismo. La adolescencia es el momento de la incoordinación, la nueva cenestesia, con la cual se inicia una nueva anarquía. Otro comportamiento -tolerado en las mujeres, y hasta mirado a veces con simpatía- es el rubor que no deja de ser en ambos sexos un signo de debilidad, timidez o incapacidad. Por el solo hecho de aparecer cada vez que el individuo debe ponerse en evidencia, ya está indicando hasta dónde su personalidad es insegura

El comienzo de la función reproductora sería esa instancia que se carga con una buena cantidad de enigmas, expuesta a tentaciones que, en el caso de aquellos adolescentes de "moral más limpia", Llega a ser percibida como que "el alma se le empaña". Dirá, incluso que, la fisiología especial de la mujer contribuye a acentuar la crueldad de ese trance: el atávico terror a la sangre refuerza la impresión de encontrarse mancillada:

"[...] esa angustia cristalizada en torno al sexo son algunos otros fenómenos de la psicología de las adolescentes, como el eclipse transitorio de la tendencia maternal [...] algo así como un olvido de la función biológica fundamental de la mujer, bajo la influencia de las solicitaciones del trabajo y del estudio [...]. Si la maternidad representa para la adolescente la fase de la plena madurez, se comprende que el rechazo de la tendencia maternal encubre una aguda nostalgia de la propia niñez [...]" (Ponce, 1934, pp. 244-247).

El elemento tan turbador como el sexo y la sexualidad estaría íntimamente enraizado en la más secreta intimidad del organismo que lleva al "descubrimiento del tiempo y de la muerte". Pero a esa expectativa en la duda se acompañaría por la ambición, a la que presenta como la expectativa del triunfo. Por eso el adolescente se engaña a sí mismo sobre los valores auténticos de su virilidad imitando malamente los signos exteriores como las fanfarronadas, las brutalidades, los atentados, las borracheras, las juergas, las jugarretas. Un momento de ilusión de la fuerza y del poder. Esa búsqueda de la emoción por lo que la emoción tiene de tónico, explicaría el amor del peligro tan característico en la juventud. Si esas conductas que quebrantaban las normas disciplinarias para Mercante eran producto del exceso de motricidad, según Ponce, se ubicaban en el terreno de las emociones: "[...] el amor del peligro, con las emociones que comporta, no es un signo de fuerza, sino de debilidad. El deprimido busca la emoción, como el toxicómano la droga" (Ponce, 1934, p. 254).

Sus rebeldías contra la regla y la autoridad de los adultos se manifiestan con la repugnancia por el medio familiar, al tiempo que surgen otros fenómenos cargados de afectividad. La tendencia social reaparece después de un eclipse transitorio. Por eso, para su seguridad, lo mismo que para su ambición, el adolescente necesita fatalmente de los otros. Pero en vez de buscar esa colaboración entre los mismos 
adultos a expensas de los cuales vivió en su infancia, sale al encuentro de otros seres, descubrirlos por sí mismo, atraerlos a la órbita de sus propios deseos, transformarlos si fuera necesario a la medida de sus propios ideales. No es la autoridad por sí misma la que provoca en él la reacción agresiva: es la autoridad fundada en razones cuya validez no le convencen. El mismo adolescente, que no soporta en su casa la indicación más ligera, no tiene inconvenientes en someterse voluntariamente a las duras imposiciones de la disciplina en los deportes; y el mismo que pisotea cuantas veces puede los derechos del adulto, se sacrifica de buenas ganas por su "team" o por su "club". Cargado por su compromiso ideológico y político el adolescente aspira a reconstruir un ambiente social sobre la base de otros adolescentes como él.

Estas conclusiones le permiten avanzar sobre la cuestión de la homosexualidad y el lesbianismo. Se pregunta: ¿Por qué aparecen en la adolescencia esos aspectos tan turbios en que la simpatía, la admiración, el amor y el amor homosexual se entremezclan y embarullan? La respuesta la encuentra en una explicación de base fisiológica: la bisexualidad inicial del organismo. Cada uno de los individuos al comienzo de su desarrollo llevaría en potencia los caracteres de ambos sexos, y sólo en cierto momento de la vida embrionaria, influencias especiales determinan el triunfo del sexo definitivo, inhibiendo o frenando al otro, aunque sin destruirlo en absoluto. Pero si la glándula vencida -restos de ovarios en el varón, restos de testículos en la mujer- ha sido capaz de imprimir al organismo púber, siquiera sea momentáneamente, la huella visible de su influencia, eso llevaría a admitir que terminará por condicionar la psiquis del adolescente:

"[...] una capacidad obtusa para el homosexualismo se insinúa [...] en el apetito consciente por el sexo opuesto que vendrá después, y por poco que la influencia del medio no venga en auxilio del adolescente -o que por razones sociales, largas de explicar, favorezcan anormalmente al sexo 'vencido' como ocurría en Grecia con las 'amistades' de la palestra y del gimnasio- la fiamma o la schwärmerei pueden ir adquiriendo, poco a poco, los matices patológicos de una inversión cada vez más aguda" (Ponce, 1934, p. 291).22

La tendencia sexual el adolescente se encuentra en la situación de un recién nacido que para saciar su hambre tuviese que aprender los movimientos de succión y deglución. Esto lo llena de temores e inquietudes. Aunque la tendencia lo arrastra fatalmente al sexo opuesto, la unión sigue siendo un misterio repleto de cosas reprochables que la religión, primero, la opinión social, después, lo habían fulminado con el horror del pecado y lo prohibido. De allí que el "deseo del sexo opuesto se

22 Cabe señalar que, a la hora de tratar esta cuestión hizo referencia al artículo de Mercante "Fetichismo y uranismo femenino en los internados educativos" publicado enArchivos de Psiquiatría y Criminología, 1905, año IV, p. 22. 
acompaña con el miedo al sexo opuesto" (Ponce, 1934, p. 358). Esa situación tan artificial no puede, naturalmente, prolongarse largo tiempo:

"Acorralado así por la sociedad y por su organismo, el adolescente encuentra entonces una solución mezquina y baja que la moral convencional aprueba. En vez de vencer la absurda repugnancia por el sexo y elevarlo a la altura de las otras tendencias, el adolescente le conserva su carácter de oprobio aunque lo sacia a escondidas en el amor venal. Para el amor venal, su sensualismo; para la novia inaccesible, la contemplación estéril. [...] no hay verdadero amor en los comienzos de la adolescencia [...] El amor solo merece ese nombre cuando la más noble intención de la ternura adquiere una resonancia orgánica en la intimidad más profunda del instinto" (Ponce, 1934, pp. 361-33).

En sintonía con la militancia feminista y, en particular, la lucha de las mujeres comunistas, dirá que el tipo de familia patriarcal ha inculcado en la mujer la idea de entrega, la obligación de adaptarse al hombre que ama. El fracaso de la familia burguesa, a cuya disolución se asistiría, habría comenzado siendo en buena parte una consecuencia del movimiento industrial del siglo XVIII que al exigir el trabajo en la mujer la separó del hogar, y le dio al mismo tiempo, un sentimiento más noble de su responsabilidad. El papel creciente que el estado asumió en la educación y cuidado de los niños, ha reducido, a su vez, la importancia del padre en la familia. El resultado fue ese poderoso movimiento femenino que, no obstante los extravíos de los comienzos, representaba "uno de los dos más generosos espectáculos del siglo". De allí su proclama esperanzadora:

"[...] A pesar de abrirse a la mujer las puertas de la universidad y la política, no por eso dejaba el hombre de exigirle la total servidumbre de su alma. [...] es necesario que la mujer comprenda que tiene deberes para con la colectividad tan urgentes como aquél, y como aquél tan nobles. [...] Sin saber nada de esas teorías, sin saber nada tampoco de sus calumniadas compañeras rusas, las adolescentes de todos los países han empezado a marchar por esa ruta. [...] la adolescente de hoy prepara noblemente la mujer libre de mañana [...]" (Ponce, 1934, pp. 363-366).

\section{A modo de conclusión}

El recorrido por la producción de estos publicitas denota el propósito que persiguieron de contribuir a la formación de los docentes, de los padres y madres y de promover el mejoramiento del sistema educativo, atendiendo las problemáticas específicas de la adolescencia. Buscaron promover la obra iluminadora de una adecuada educación. De allí que no soslayaron la cuestión de la sexualidad, en muchos casos con la intención de favorecer las prácticas de intervención positiva que 
promovían los eugenistas argentinos. Si para que imperara el orden era inminente salvaguardar la salud moral del cuerpo de la nación, el tema de la sexualidad no podía soslayarse ni ocultarse. Así, esa notable producción de conocimiento en torno al sexo y la sexualidad, más allá de las propias trayectorias personales y disciplinares, respondía a ese clima cultural y al contexto social.

Los temores giraban en torno a los tópicos centrales de cómo prevenir el delito de la procreación que promovía la degeneración de la raza y la erradicación de una sexualidad patológica. Sin lugar a dudas, aquellas prácticas vergonzantes eran propias de un cuerpo social enfermo, débil condicionado por las influencias malignas. La pubertad aparecía entonces como la metáfora de ese cuerpo social. Los púberes se revelaban como seres incompletos, influenciables y expuestos a los reclamos del instinto sexual. Si bien eran cuerpos débiles, condicionados por el ambiente social en el que se movían, por otra parte, aparecían como maleables, factibles de ser formados en la "normalidad". En la pubertad, ya fuera una etapa de "cretinismo transitorio" (Mercante) o de angustia y de recogimiento a una vida interior (Ponce), tal parecía que se advertía una tendencia a identificarse con los y las pares de su propio género. Así, corrían el riesgo de no formase adecuadamente para el ejercicio de una paternidad y una maternidad responsable, además de ser proclives a transitar experiencias peligrosas como el onanismo, la homosexualidad y el tercer sexo. Por eso, la escuela debía acompañar con una adecuada formación de una sexualidad responsable que configurara la identidad masculina y femenina sin fisuras.

\section{Bibliografía}

Armus, D. (2007). Un Médico Higienista Buscando Ordenar el Mundo Urbano Argentino de Comienzos del Siglo XX. Salud Colectiva, 3 (1), 71-80.

Barcos, J. (1925). Libertad sexual de las mujeres, Buenos Aires, Argentina: s/e.

Barrancos, D. (1990). Anarquismo, educación y costumbre en la Argentina de principios del siglo. Buenos Aires, Argentina: Editorial Contrapunto.

Barrancos, D. (1991). Contraconcepcionalidad y aborto en la década de 1920: problema privado y cuestión pública. Estudios Sociales, l (1), 75-86.

Barrancos, D. (2001). Moral sexual, sexualidad y mujeres trabajadoras en el período de entreguerras (pp. 198-225). En Devoto, F.y Madero, M. (directores). Historia de la vida privada en la Argentina, V. 3, Buenos Aires, Argentina: Taurus.

Butler, J. (1999). Gender Trouble. Feminism and the subversion of Identity. Nueva York: Routledge.

Camaña, R. (1916). Pedagogía Social. Buenos Aires, Argentina: La Cultura Argentina.

Dagfal, A. (2009). Entre París y Buenos Aires. La invención del psicólogo (1942-1966). 
Buenos Aires, Argentina: Paidós.

Darré, S. (2005). Políticas de género y discurso pedagógico. La educación sexual en el Uruguay del siglo XX. Montevideo, Uruguay: Ediciones Trilce.

Di Liscia, M. S. y Salto, G. (Eds.) (2004). Higienismo, educación y discurso en la Argentina, 1870-1940. Santa Rosa, Argentina: EDULPAM.

Donzelot, J. (2007). La invención de lo social. Ensayo sobre la declinación de las pasiones políticas. Buenos Aires, Argentina: Ediciones Nueva Visión.

Fernández Cordero, L. (2017). Amor y anarquismo. Experiencias pioneras que pensaron y ejercieron la libertad sexual. Buenos Aires, Argentina: Siglo XXI.

Foucault, M. (1991). Historia de la sexualidad 1. La voluntad del saber. México DF, México: Siglo XXI.

García, L. (2020). Aníbal Ponce y la Psicología. Un análisis histórico. Revista Integración Académica, 8(22). Recuperado de https://integración-académica.org/ vollnumero2-2013/19.

Ledesma Prietto, N. (2017). La revolución sexual antes de la revolución sexual. Discursos de los médicos libertarios sobre el placer (Argentina, 1930-1940). Sexualidad, Salud y Sociedad, 26, 148-170. Recuperado de https://doi.org/10.1590/1984-6487. sess.2017.26.08.a

Lionetti, L. (2006). Víctor Mercante: agente político e intelectual del campo educativo en la Argentina de principios del siglo XX. Prohistoria, 10, pp. 93-112.

Lionetti, L. (2007). La misión política de la escuela pública: educar al ciudadano de la República. Buenos Aires, Argentina: Miño y Dávila.

Mercante, V. (1918) La crisis de la pubertad y sus consecuencias pedagógicas. Buenos Aires, Argentina: Ediciones Cabaut y Cía.

Miranda, M. y Vallejo, G. (Dir.) (2012). Una historia de la eugenesia: Argentina y las redes biopolíticas internacionales, 1912-1945. Buenos Aires, Argentina: Biblos.

Múgica, M.L. (2017). "Representaciones y guías de comportamiento sexual para mujeres $y$ varones en la Argentina en el siglo XX. Manuales y problemas sobre el asunto". XIII Jornadas Nacionales de Historia de las mujeres. VIII Congreso iberoamericano de Estudios de género: "Horizontes revolucionarios. Voces y cuerpos en conflicto" 24 al 27 de julio de 2017 Instituto Interdisciplinario de Estudios de Género (FFyL UBA) Instituto de Investigaciones Gino Germani (FSOC-UBA) Cátedra de Géneros y Sexualidades (UNQ), Buenos Aires-Quilmes, 24 al 27 de julio, 2017.

Morgade, G. (coord.) (2016). Educación sexual integral con perspectiva de género: la lupa de la ESI en el aula. Rosario, Argentina: Homo Sapiens. 
Nari, M. (1996). Las prácticas anticonceptivas, la disminución de la natalidad y el debate médico, 1890-1940 (pp. 151-189). En Lobato, M. Z. (ed.). Política, médicos y enfermedades. Lecturas de Historia de la salud en la Argentina. Buenos Aires, Argentina: Biblos.

Nari, M. (1999). La eugenesia en la Argentina 1890-1940. Revista Quipu, 12 (3), pp. 343369.

Nouzeilles, G. (2003). An Imaginary Plague in Turn-of-the-Century Buenos Aires: Hysteria, Discipline, and Languages of the Body (pp. 51-74). En Armus, D. (Ed.). Disease in The History of Modern Latin America. From Malaria to Aids. Durham, USA: Duke University Press.

Pita González, A. (2012). De la Liga Racionalista a cómo educa el Estado a tu hijo: el itinerario de Julio Barcos. Revista De Historia, n. ${ }^{\circ}$ 65-66 (enero), 123-4l. Recuperado en https://www.revistas.una.ac.cr/index.php/historia/article/view/5068.

Ponce, A. (1974 [1936]). Ambición y angustia en los adolescentes. En Obras Completas (pp. 493-605), Tomo 2, Buenos Aires, Argentina: Editorial Cartago.

Queirolo, G. (2013). Género y sexualidad en tiempos de males venéneros (Buenos Aires, 1920-1940). Nomadías, 17, Recuperado en https://nomadias.uchile.cl/index.php/ NO/article/view/29939

Ramacciotti, K. (2018). Telma Reca en la gestión estatal de la sanidad argentina (19301948). Asclepio, 70(1), p211. https://doi.org/10.3989/asclepio.2018.04

Rubin, G. (1986). El tráfico de mujeres. Notas sobre la "economía política del sexo". Nueva Antropología, 30 (VII), pp. 95-145.

Sardú, A. (2008). Una molesta piedra en el camino: educación Anarquista. Revista THEOMAI, 17, primer semestre. Recuperado en: https://www.romaevista-thei.unq. edu.ar/numero17/ArtSardu.pdf

Stepan, N. (1991). The Hour of Eugenics. Race, Gender, and Nation in Latin American., Nueva York, USA: Cornell University Press.

Suriano, J. (2004). Anarquistas, cultura política y libertaria en Buenos Aires, 1890-1910. Buenos Aires, Argentina: Editorial Manantial.

Tedesco, J. (1986). Educación y Sociedad en la Argentina (1880 - 1945), Buenos Aires: Argentina: Editorial Solar.

Vezzetti, H. (2004). Los comienzos de la psicología como disciplina universitaria y profesional. En Neiburg, F. y Plotkin, M. (comps.) Intelectuales y expertos. La constitución del conocimiento social en la Argentina (pp. 293-326). Buenos Aires, Argentina: Paidós. 
Weeks, J. (2014). Sex, Politics and Society The regulation of sexuality since 1800. London and New York, USA: Routledge. 